\title{
Knowledge, power and the ethics illusion: Explaining diverse viewer interpretations of the politics in classic era Doctor Who
}

\author{
Vanessa de Kauwe and Lindy A. Orthia \\ Australian National Centre for the Public Awareness of Science \\ The Australian National University
}

\begin{abstract}
What is the dominant political ideology of Doctor Who (1963-89; 1996; 2005-)?

Scholars and viewers have variously claimed the programme represents political positions ranging from far right to far left, or have denied it is political at all. In this article we offer a structural analysis that partially explains this diversity of response. Analysing three classic era Doctor Who serials with different political flavours, all of which feature political regime change as a narrative element, we identify two narrative devices that function to obscure any political ideologies present. The first, which we call the 'science-beats-tyranny' template, foregrounds the problem of a tyrannical regime rather than exploring any political alternatives to it. It circumvents the need for political debate by deposing the tyrant with a scientific fix. The second, which we call the 'ethics illusion', uses heuristic logic to effect the appearance of an ethical plot resolution, while skipping over the political details of the new regime replacing the tyrant. We argue that these devices create ambiguity about a serial's political commitments and also direct viewer attention to generic rhetoric about freedom from tyranny, rather than any more specific political ideology.
\end{abstract}

\section{Keywords}

Doctor Who, ethics, politics, science, structuralist narratology, ambiguity

\section{Introduction}

Is Doctor Who (1963-89; 1996; 2005-) political? In a 2004 article, Alan McKee attempted to answer that very question. To do so he interviewed Doctor Who fans about their perceptions of the politics in the show - at that point only the original, or 'classic', series (1963-89) - and the politics embodied by its main character, the Doctor. McKee sampled a cross section of viewers who had political views extending from Marxist to the extreme right. He concluded that neither the Doctor nor the programme could be tied to a particular political stance. In general, viewers saw the programme as non-political or saw in it what they saw in themselves, with representations of its politics interpreted as ranging from left to right accordingly. They unanimously saw the Doctor as ethical, as always in a struggle against evil, but not necessarily political. Thus McKee concluded that the show is bereft of any particular political position. Doctor Who seems to embrace all political views and therefore none. 
This may come as a surprise to viewers who feel strongly that classic era Doctor Who says something specific about politics. In recent decades, media scholars and Doctor Who fans have spent much energy articulating what they thought the show's core political ideology was. James Chapman (2006: 7) expressed the view that, on average, the classic series' political bent is liberal, with the Doctor standing for 'liberty, freedom, equality, justice and tolerance' and opposing 'totalitarianism, slavery, inequality, injustice and prejudice'. The programme's overt rhetoric opposes social oppression such as sexism or racism, although its production choices often, perhaps inadvertently, reflect oppressive attitudes of the same kind (Orthia and Morgain 2016). John Fiske (1984) asserted that popular texts, including Doctor Who

[...] are constructed from those areas of discourse where consensus is high enough to be taken for granted - thus we find [the Doctor] defined partly through democracy in the political discourse and his adversaries through totalitarianism, because these signs can be taken for granted. (169-70)

Thus on average the programme seems to take a middle-ground approach, safely reflecting an average British political status-quo, no doubt bound by the constraints placed upon its producer the $\mathrm{BBC}$, which is beholden to British taxpayers, governments, and ratings pressures (Tulloch and Alvarado 1983; Gregg 2004).

Burrowing down to the level of individual serials, scholars have identified more subtle and varied political meanings in the classic era. For example, Chapman (2006: 90) called 'The Green Death' (1973) 'perhaps the most politically radical of all Doctor Who stories' because the narrative sets the environmental lobby against corporate capitalism and 'sides unequivocally with the environmentalists'. John Tulloch (1995: 68) argued that 'The Monster of Peladon' (1974), which depicts a fictitious group of miners sympathetically but opposes worker militancy among them, 'is an unusually overt [text] in terms of its political statements'. On the other hand, Fiske (1984) and Lindy Orthia (2013) both found 'The Creature from the Pit' (1979) to be more right wing, because it aggressively advocates free market economics and western-style technological development. Peter Gregg (2004) linked 'The Ark in Space' (1975) to social anxieties about Britain's loss of global economic power and entry into the European Economic Community, reflected in the serial's optimistic depiction of future humanity as British. Similarly, Vanessa de Kauwe (2013) identified British discomfort with postcolonial poverty and diasporic migration in 'The Ark in Space', through its depiction of a hostile alien species, displaced by human imperialism, now seeking a new home on Earth. Perhaps it is true to say that while on average Doctor Who has no consistent political orientation beyond a broadly liberal democratic British status-quo position, individual stories seem to encode specific political meanings that go beyond that consensus.

This range of political meanings expressed by different serials is probably one reason McKee's viewers disagreed on whether the programme leans to the right or the left. Another is the widely-established media studies truism, based on Roland Barthes' 1967 assertion of 'the death of the author' (Barthes 1988), that no text has a single, fixed meaning, and each viewer will interpret what they see through a different lens of sociocultural positionality, experiences and interests. McKee (2004: 213-215) preferred this interpretation, discussing it at length.

In speculative texts such as Doctor Who this is further complicated by the use of allegories to encode ideological messages about the real world. Viewers may interpret such allegories in different ways, or accept story events and characters at face value without 
reading them as allegories, rendering any intended political meanings invisible (Lavender 2009, Orthia 2013). Jane Espenson, a scriptwriter for the new Battlestar Galactica (200409 ), has commented on her deliberate use of this when engaging in heavy political critique:

Oh I think the thicker the metaphor, the more there are robots, or monsters, or big dinosaur puppets $[. .$.$] the more there is eye candy and clear science fiction or fantasy$ elements, the more you can get away with. In a way, sort of the more heavy handed you can be, the more overt you can be, because people are distracted. (interviewed by Chow-White et al. 2015: 1215)

These factors surely contributed to producing the diversity of viewer interpretations McKee documented. However, put together, they only really amount to an assertion that texts are different and people read them differently. While this is of course true, we agree with Fiske's (1984: 171) rather old-fashioned structuralist argument that texts are not wide-open to all potential meanings; rather 'the structures of the text itself prefer some potential meanings over others and delimit the space within which meanings can legitimately be found'. In this essay we describe a particular narrative structure that obfuscates political ideologies in some Doctor Who serials, rendering them politically ambiguous. By 'political' we restrict ourselves here to discussing ideologies of societal governance and political economy.

Structuralist approaches to thematic analysis have been outmoded since the 1980s because they are seen to overdetermine meaning and ignore viewer response, and Fiske's structuralist analysis of Doctor Who has been criticized for these reasons (and others, see McKee 2004: 212-13, Speaker to Animals n.d.). However, here we use structuralism for narratological description, rather than for thematic analysis or evaluation (Herman 2010, Selden 2014). Accordingly, we do not claim that our political interpretations of the serials we discuss are definitive, nor do we judge their political merits. Our approach complements rather than contradicts the notion that viewers have interpretive freedom, because we argue that the structure we describe facilitates diverse viewer interpretations (though we do not document viewer responses here, drawing instead on McKee's interviews).

The structure we identify is comprised of two related narrative devices that we call, respectively, the 'science-beats-tyranny' template and 'the ethics illusion'. We demonstrate their presence in three classic era Doctor Who serials: 'The Krotons' (1968-69), 'The Green Death' (1973) and 'Terminus' (1983). We chose these serials for a similarity and a difference between them. The similarity is that all three depict an explicitly political subject matter: the transition of power from one regime to another; a local revolution of sorts. In each case this transition is framed by the narrative as a morally good outcome, because it involves an oppressed group overthrowing a tyrannical oppressor. The serials thus differ from other kinds of Doctor Who stories, such as those about preserving a regime under threat, in which preventing regime change is framed as morally good (e.g. preventing alien invasion).

However, the key difference between our three serials is the nature of the new political regime established after defeating the oppressor. Respectively, we categorize those new regimes as hereditary oligarchy, technocracy and collectivism. Nevertheless, as we argue, their political commitments are ambiguous, so our classification is open to debate. Given the regime changes are all framed as morally good, we suggest that each of these various new political systems is implicitly endorsed or at least accepted by the serial it appears in. But as we will show, the science-beats-tyranny template and the ethics illusion obfuscate those new ideologies, making the serials more politically ambiguous. Our point is to demonstrate that the structures we describe play a role in particular forms of Doctor Who 
texts, obscuring their political commitments no matter which side of the political fence they fall on. This helps explain McKee's unexpected results.

\section{Science-beats-tyranny and the ethics illusion}

The science-beats-tyranny template is a particular approach to telling stories about regime change. In this approach, the narrative structure emphasizes overcoming the immediate problem - eliminating the tyrannical oppressor - without imagining what will become of the oppressed people. In other words, the focus is on the old regime rather than the new. This is consistent with Laura Geuy Akers' (2010) characterization of the Doctor's ethics as an ethics of care, focused on the needs of particular people in the here and now, rather than abstractions. Accordingly, a large proportion of screen time is spent exploring the terrible consequences of the oppressor's tyrannical actions, and searching for a tool to defeat the oppressor. In the serials we discuss, science provides that tool, hence the name of our template, 'science-beats-tyranny'. This template has the benefit of appealing to almost every possible viewer since opposing tyranny and supporting science are recognized as high consensus ideological positions shared across the political spectrum. Almost everyone objects to cruelty and totalitarianism as Fiske (1984) noted, and notwithstanding generations of scholarly insights into science's political nature (e.g. Merchant 1980; Harding 2008), science is conventionally characterized in the public domain as objective and value-free and therefore apolitical: a useful tool for everyone (Walker 2007; Meyer 2016). Each story we discuss thus appears to be a simple tale of overcoming tyranny through the expert application of technical knowledge, with minimal screen time spent exploring the details of political disputes or the politics of the new regime.

The science-beats-tyranny template is a helpmate to our second device, the ethics illusion, a heuristic that gives the story's resolution an ethical veneer. Science's role in the narrative supports the maxim frequently expressed in Doctor Who, that knowledge is power. Defeating an oppressor with scientific knowledge forges a positive association between knowledge and ethics. This is reinforced by the Doctor's strong scientific (and other) knowledge, and his characterization as ethical (Tulloch and Alvarado 1983; McKee 2004; Britton 2011). In our example serials, the alternative leaders rising up against their oppressors are also presented as morally good and scientifically trained or sympathetic to science. Conversely, the oppressor's power in each case is characterized by the apparently unethical suppression of knowledge. The result is a three-way positive association between gaining knowledge, taking power, and behaving ethically.

Yet not discussed in our three serials is the fact that wielding knowledge to assert power is not necessarily ethical in itself. Therefore ethical questions may remain about the serials' resolutions. As Piers Britton (2011: 213) observed, 'the status quo established by the Doctor at the end of many stories is understood to be politically correct and ethically sound', but 'this assumption does not always withstand close scrutiny'. The emphasis on effecting a regime change by scientific means creates the impression that revolution is a technical problem, circumventing any moral debates about revolutionary action. As a result, the serials are missing an ethical evaluation of the kind of political regime that comes to power. The stories' moral trajectory relies upon viewers making a heuristic leap between knowledge, power and ethics, and concluding that the final result is ethically good, without interrogating this conclusion. We call this narrative trick 'the ethics illusion' because knowledge, power and ethics are so melded in the storyline that the viewer is never encouraged to ask, 'whose power?', 'what knowledge?' and 'how are we to gauge the ethics of this?'. We contend this 
narrative device may be partly responsible for the lack of consensus around the political commitments of Doctor Who.

We acknowledge that the science-beats-tyranny template fulfils a pragmatic requirement of television serials by providing a timely, satisfactory resolution to the story, where a protracted political fight would not meet this need. In that respect its presence is not surprising. Nevertheless it enables the serial to downplay ethical questions about the new regime. The resultant ethics illusion is therefore the primary innovation of our article, but exploring the mechanics of the science-beats-tyranny template is also important for understanding how the ethics illusion is produced.

\section{The Krotons}

'The Krotons' provides the most clear-cut case for the science-beats-tyranny template and the ethics illusion. We examine it in depth and treat the other serials more briefly because of space constraints.

The serial begins when the Doctor and his companions arrive on the planet of the Gonds, whose culture revolves around obeying their non-indigenous masters, the mysterious Krotons. The Krotons arrived millennia ago, killing hundreds of Gonds and poisoning the land. Since then they have lived within their ship, which the Gonds call 'the machine', and have not been seen. Yet they rule the Gonds via voice commands, through which they cultivate fear of another cataclysm. The Gond leader, Selris, tells the Doctor that all the Gonds' laws, science and culture have come from the machine. That is, the Krotons control their knowledge.

The Krotons' orders focus on two aspects of law. First, they forbid the Gonds from entering the 'wasteland' where the first cataclysm occurred, by perpetuating the belief it is still poisoned. Second, they control the Gonds' education and prohibit certain topics, notably chemistry. Periodically the Krotons test Gond students and order the best trained to join them in the machine. The students are never seen again. As the story progresses, it is revealed that the Krotons are a crystalline, tellurium-based life form whose ship and bodies were damaged thousands of years ago, and they need 'mental energy' from intelligent beings to restore themselves. This explains their laws: after training young Gonds they extract the top students' mental energy, then kill them in the wasteland.

The Doctor and companion Zoe discover this after rescuing a student from extermination once her mental energy had been extracted. They then analyze a chemical sample from the Krotons' machine, and, recognizing its tellurium base, the Doctor realizes the Krotons and their ship can be dissolved by sulphuric acid. This explains why studying chemistry was forbidden. He develops a sulphuric acid-based formula with help from the Gond named Beta, an aspiring scientist, and helps the Gonds use it, ending the Krotons' tyrannical reign. The science-beats-tyranny template thus provides the narrative's primary impetus.

Driving home the message that defeating the Krotons is a blow against tyranny, a liberatory aesthetic is created for the serial through the language of freedom in character dialogue. For example, several characters declare they 'want to be free of the Krotons', having 'been slaves for a thousand years'. When the Krotons die, Selris's son Thara declares, 'We're free at last'. Similarly, linking knowledge to freedom, Beta despairs that 'we only know what the Krotons tell us - we don't think, we obey', but now he is free to 'discover truth for [himself] instead of being fed information like a dog with scraps'. Selris, Thara and Beta are thus explicitly linked to words which signify freedom. 
What political messages are encoded in this primary narrative then, aside from a generic counterposition of freedom against tyranny? If viewed as an allegory for real life politics, one might interpret the Krotons as a colonial power or corporate capitalism, investing resources in educating a colonized/working class population to identify potential leaders and co-opt them for its own ends. Indeed, some commentators have connected this serial to the South African apartheid regime (Chapman 2006: 70). There is also a parallel with the notion discussed by Noam Chomsky of a fragmented education system under capitalism, in which education for working people is designed to impose obedience, while intellectual elites are rewarded with creativity and independence of thought if they use their education to bolster the capitalist system (Chomsky 1996: 46). George Orwell's (1946) thinking about politics and language is also relevant here: a corrupt regime brings a suppression and corruption of thought which in turn maintains the corrupt regime. Making these links suggests the Krotons can be viewed as similar to real life totalitarian dictators.

However, an allegorical reading such as this can only extend so far. Once the Krotons are revealed to be physically vulnerable to sulphuric acid, the parallel with capitalism, colonialism or totalitarianism becomes less convincing, since none of these powers can be defeated with such a simple application of scientific knowledge. The scientific logic the plot relies upon reminds us that the Krotons are a tellurium-based alien species: a fantasy not an allegory. They are tyrants without political context, an apolitical evil. The story can be comfortably interpreted in terms of a simple ethics of freeing one fictitious species from a tyrannical other. The Krotons' defeat by objective science circumvents the need for a protracted and bloody war, as might be expected in real situations of oppression. So although the allegory suggests a political message, the narrative's resolution departs from the possibility of a political solution to the problem. Any impetus to revolution in the talk of freedom and slavery is superseded by scientific expertise. This primary narrative, then, does not obviously represent any particular political position or ideology, aside from a commitment to science and opposition to slavery. Already this helps explain why viewers might interpret the politics of this serial differently.

The political ideology of the new regime replacing the Krotons' rule is not discussed at length either, but a subplot featuring a group of Gonds rebelling against Selris's leadership provides a glimpse of it. The rebel leader, Eelek, gains support of the Gond Council, deposes Selris as Council leader, tells the truth about the Krotons to the Gond population and plans an attack on the machine. Selris and Beta criticize his actions throughout: council leadership is hereditary so only Thara can replace Selris; Eelek's attack is doomed because of the Krotons' superior technology; and telling people the truth about the Krotons is dangerous because it inspires resistance. At the end of the story, after both Selris and the Krotons die, Thara asserts that dealing with Eelek 'will be my pleasure. I shall take over from my father as leader of the Gonds, whatever Eelek thinks'. Eelek is thus constructed as a minor villain, compared to the supposedly rightful leadership of Selris, Thara and Beta. In this concerted suppression of Eelek, the Doctor's allies share traits with real world totalitarian regimes: when a group finds itself under threat, the leaders of that threatened group may suppress their own people in order to maintain leadership, sacrificing democracy (Agamben 2002). In other words, the new society coming into being after defeating the Krotons involves a hereditary oligarchy, openly suppressing popular dissent and controlling information to prevent the public from reacting undesirably. This seems far from the Gonds' liberatory rhetoric and seems like something the Doctor would normally object to.

However, as noted, this new political regime is not foregrounded within the narrative. It is not necessary to follow Gond political machinations to understand or enjoy the story's climax; one has to pay close attention to even see them. The emotional impetus instead maps 
onto the science-beats-tyranny template, which shows us that knowledge is power and that it is ethical to wield knowledge to effect freedom from tyrannical oppressors and in doing so to reclaim power. This overshadows any more complex debate about the ethics and politics of the new regime. Instead, the narrative structure creates an ethics illusion: the impression that the new regime is morally good because it has replaced a tyrannical regime via the application of objective knowledge.

A critical factor propping up the ethics illusion is the Doctor's apparent lack of opinion about the new regime. He chooses to fight against the Krotons, but not in favour of Eelek and the other Gonds suppressed by their own oligarchy. As a result, the Gonds' political debates are flagged to viewers as unworthy of ethical scrutiny because the Doctor does not get involved in them. Arguably this focus on the common enemy is an example of what Akers (2010) called the Doctor's 'ethics of care', and what Kevin S. Decker (2010: 135) called the Doctor's 'ethics of ambiguity': a combination of the 'ideal of embracing selfrealization [and] the existentialist's cosmic angst'. Under both characterizations the Doctor's ethics are explicitly not tied to a particular political programme. Instead, according to Decker, the Doctor is guided by the existentialist freedom to choose his own ethical stand amongst the myriad possibilities open to him, and to act accordingly. His ethics, then, are an ethics of the self, hidden behind the primary narrative. Because they are hidden and not associated with a particular political ideology, they may be difficult for viewers to take issue with or even to characterize.

These dynamics show how a component of a serial can encode a specific political point of view, while overall the serial appears not to adhere to a particular ideology. Viewers may incorporate their glimpses of the new regime's politics into an assessment of the serial's politics, arriving at different conclusions about its meaning. Or they may overlook the political ideologies encoded in the new regime altogether, because the narrative is structured to downplay them.

\section{The Green Death}

Of our three serials, 'The Green Death' is the most overtly political because it is set on Earth in the present day, makes reference to real political entities including the United Nations, and celebrates political movements that advocate environmental sustainability. As noted in our Introduction, Chapman (2006) argued it is the most radical Doctor Who serial for these reasons. However we contend this impression of a 'radical' political orientation is partly a product of the ethics illusion, because its narrative structure subordinates antidemocratic elements of its plot to the science-beats-tyranny template, rendering them less visible.

We agree with Chapman that the scenario engages with radical social movements of the time by pitting a profiteering petroleum-producing corporation, Global Chemicals, against a small group of environmentalists and scientists from a local commune, Wholeweal. The serial does side with the environmentalists, particularly through Wholeweal biochemist Professor Cliff Jones, a young Nobel Prize winner who is developing a new variety of fungus to feed the world in place of meat. A scene in which the Doctor's companion Jo describes Cliff as a younger version of the Doctor frames Cliff as a 'hero' in the story rather than a bystander or a 'villain'.

As in 'The Krotons', the narrative in 'The Green Death' is driven by a science-beatstyranny impetus. The story begins with Global Chemicals secretly pumping its bright green refinery waste down an old coal pit, killing three ex-miners. The waste also creates giant maggots that contaminate the landscape, one of which bites Cliff, who almost dies from the 
same 'green death' as the miners. In the end it is Cliff's fungus that cures the illness and kills the maggots. Science of a sustainable variety is thus foregrounded as a solution to the problem of corrupt, unregulated, polluting industry.

Several plot elements characterize Global Chemicals as tyrannical, including its secrecy, its executives' cruel disinterest in the sick miners and Cliff, and their powerful ability to phone the British Prime Minister for favours. Most importantly, it is revealed that a computer called BOSS, not a person, runs the company. BOSS turns its staff into obedient zombies and plots global domination to improve 'efficiency, productivity and profit'. It is discursively linked with Nazism, when it uses German words ('The day is coming fast. DDay. Der Tag'), spouts Nietzschean terminology ('my little superman' and 'good little Nietzschean') and becomes obsessed with triumphalist classical music. It is the form of extreme Nietzschean nihilism recognized by Adam Riggio (2010: 252-55) in other Doctor Who narratives. BOSS is ultimately blown up by Global Chemicals' Director, Stevens, when the Doctor helps Stevens recover from BOSS's hypnotism and feel regret for the suffering he caused. The exact nature of the evil Global Chemicals represents is ambiguous: it may be read either as exemplary of corporate capitalism, or as an atypical aberration because of its mad Nazi computer boss. Either way, Global Chemicals can easily be recognized as tyrannical.

Once again, most of the serial's screen time is devoted to exploring the problems caused by Global Chemicals, finding short-term solutions to them, and uncovering BOSS's true nature. Once again, the need for extended political action is circumvented by a technical solution, in this case Cliff's fungus and the Doctor de-zombifying Stevens. Even Stevens' final reclamation of his humanity is driven by an awareness of the suffering BOSS caused, rather than an alternative vision of the future. All of this follows the science-beats-tyranny template in emphasizing the problem and immediate antidote, without a long term vision.

There is a slight caveat to this because the Doctor, Jo and Cliff spend considerable screen time discussing sustainable technologies, industrial pollution and the evil of profitmotives. In this sense Chapman is correct: the serial paints a picture of the future as built on renewable energy, new food sources, and the public good as a driver of research. These characters' commitment to these ends, their active opposition to the totalitarian inclinations of Global Chemicals and their scientific expertise together forge the same positive relationship we saw in 'The Krotons' between gaining knowledge, taking power and behaving ethically. The heuristic reasoning linking these factors creates an ethics illusion; the appearance of an ethically sound narrative resolution with the end of Global Chemicals. However, this democratic political flavour is not matched in every aspect of the plot. As with 'The Krotons', the politics of the regime coming into power at the end is de-emphasized by the narrative structure, and it carries a different kind of political message.

The serial's coda sees the United Nations recognizing Wholeweal as a 'Priority One Research Complex'. Cliff, overjoyed at this news, declares it means 'unlimited financial help', 'work for the valleys' and 'food for all the world'. This ending implies a new regime for the community but does not explore its implications. For example, the phrase 'work for the valleys' may imply Wholeweal will be the miners' new employer. This could be a positive in that their work will be public-funded and useful, and the Wholeweal scientists seem nice people, so we may hope they will be kind and fair employers. Wholeweal's communal governance model might even be extended to a larger group, including the miners. Nevertheless, there is a sense in which the miners don't have much choice in the matter, or control over the enterprise they will be working for. Scientists, rather than capitalists or the British Government, will control the local economy, suggesting an element of technocratic rule. 
More overtly undemocratic than this, Jo reveals she asked her highly placed uncle to secure the unlimited UN funding for Wholeweal, after she became engaged to Cliff. The new regime is therefore nepotistic as well as technocratic, carrying echoes of the Gond hereditary oligarchy. It has a non-elected body in the top decision-making position: the United Nations, whose non-elected nature has been questioned by scholars and extremist politicians alike (Vibert 2007; Hutchens 2016). Yet the Doctor's benign congratulations to Cliff, and his complicity in Jo's nepotism, mark these aspects of the new regime as unworthy of further ethical interrogation. In recognizing the nature of this new regime, we can see that the ostensible radicalism of 'The Green Death' really extends only to its environmental stance, not other aspects of politics. The ethics illusion obscures political contrivances that stray far from surface appearances.

\section{Terminus}

Our third serial is set on a hospital space station called Terminus, run by Terminus Incorporated, a private company. The station supposedly provides a cure for Lazar's disease, a form of space leprosy, but in reality the radiation-based cure is uncontrolled and kills many patients. The problem is that the Terminus staff are all slaves, so they cannot change anything about how the station is run. The medical officer, a giant creature called the Garm who can live in the irradiated environment, is slave to an electronic box controlled by the station's orderlies, a demoralized bunch of ex-soldiers called the Vanir. In turn, the Vanir are slaves to a drug called hydromel, manufactured by the company and shipped to them from afar. No company representatives ever appear, but the material dependence on hydromel is sufficient to secure compliance.

The serial contains two parallel primary narratives. In the first, the Doctor accidentally starts a cataclysmic chain reaction, and needs the Garm's great strength to stop it, so he uses the electronic box to gain control of the Garm's labour. The Garm then asks the Doctor to free him by destroying the box, which he does. In the second narrative, the Doctor's biochemist companion Nyssa becomes infected by Lazar's disease. After successfully undergoing the treatment, she realizes the enslavement of both Garm and Vanir is the core problem and that the cure could work if they were free to modify and regulate it. She makes them an offer to help change the station, by using her biochemical expertise to manufacture hydromel, and they accept. By adopting this home-grown hydromel source, the Vanir are freed from dependence on the company and can make Terminus a genuine working hospital. At the end of the serial Nyssa remains on the station to work with the Vanir and Garm to cure the Lazars.

Once again the science-beats-tyranny template dominates the narrative. Nyssa's scientific knowledge is the key to breaking Terminus Incorporated's control of the Vanir thus enabling their freedom. The other major narrative, freeing the Garm, does not involve science, but it does resolve the highly political problem of economic enslavement with a simple technical solution - destroying a box. In both cases, the political complexities of revolutionary struggle are circumvented because all that is required to eliminate the tyrannical regime is scientific expertise and an act of common humanity. Once again the ethics illusion comes into play at the nexus of scientific expertise, ethical actions, and a change of regime.

However, again the politics of the new regime are left unexamined by the serial. Arguably Nyssa, the Garm and the Vanir begin to create a worker's collective of sorts, since they will be working as equals to make the station effective, each contributing different 
expertise. If read this way, 'Terminus' seems to champion a collectivist ideology. But this is not articulated or explored, and the new regime could equally be read as hierarchical or at least unstable with the Vanir now dependent upon Nyssa. Philip Sandifer (2012) noted of 'Terminus' that it was more overtly 'a Marxist Norse space opera' in the original script before this tone was edited out for the final production. The final production is structured to downplay this aspect, and once again the Doctor does not interrogate the new regime's ethics or politics beyond telling Nyssa she is brave and admirable. Viewers are then free to imagine the details of the new regime themselves or to ignore it and focus on the dominant sciencebeats-tyranny component of the narrative.

\section{Conclusion}

The narrative dynamics we have explored show how difficult it can be to narrow down the political meaning of a Doctor Who serial to a specific single ideological viewpoint. Viewers may find different political meanings depending on which part of the serial they focus on, or they may find no particular political ideologies at all if they read the story in a certain way.

The programme's focus on solving immediate problems rather than imagining longterm possibilities allows it to avoid asserting a commitment to any political programme, beyond the generic elimination of tyranny and embrace of freedom. This is broadly consistent with Fiske's (1984) assertion that the programme's explicit political messages resonate with high consensus concepts such as support for democracy and opposition to totalitarianism. Particularly attentive viewers may ask questions about the new regimes coming to power, and thereby find more extreme or more specific political positions. But the narrative is structured to avoid close interrogation of these, and the lack of screen time devoted to them leaves substantial political ambiguity about the outcomes. Even if the new regimes can be labelled with words like 'hereditary oligarchy', 'technocracy' or 'collectivism' as we have done here, the details are downplayed by the dominance of the science-beats-tyranny template and the ethics illusion heuristic. Viewers are left to either imagine what the new society might be like by filling in the gaps themselves, or to ignore it. This obfuscating structure relies upon the programme's subtle characterization of the Doctor as adhering to an ethics of care (Akers 2010) or an ethics of ambiguity (Decker 2010), rather than adhering to any recognizable external political ideology. The Doctor's function as the narrative's ethical compass is crucial for guiding viewers' attention to some political problems and not others.

Our three serials feature science at the centre of their stories, enabling us to identify the science-beats-tyranny template from them. Science is significant because it is of prominent value in Doctor Who (Orthia 2011). It is a leading characteristic of the Doctor: proverbially his 'weapon of choice' when action is needed. More specifically, in our three serials, science is not allegorized: science in our world is the same as science in the worlds of the serials. Furthermore, as discussed in our Introduction, science is commonly characterized as apolitical. The role of science in defeating the tyrants circumvents the need for the political debates and actions that would be needed to fight tyranny in the real world, rendering these stories less overtly political than one might expect for stories about regime change.

Beyond these particular serials, the template might be retuned by replacing science with another story element that appears apolitical, particularly one involving specialized knowledge or skill. For example 'the Force' in Star Wars (Lucas 1977) serves the same function: it solves a political problem with a simple, technical solution which overshadows 
any underlying political ideologies in the text, in terms of narrative prominence. A similar Doctor Who example is the use of meditation in 'Snakedance' (1983). Star Wars also uses symbolic, strategic acts of violence, as have numerous other classic era Doctor Who serials not reliant upon science. Revolutionary action has driven regime change in several Doctor Who serials about colonialism, but even they mostly focus on dethroning the tyrant, not the messy postcolonial details of the new society (Orthia 2010; see also de Kauwe 2013).

Whatever the tool, most regime change-themed serials follow a similar narrative structure, with the same ambiguity about the new regime's political commitments. Occasionally that ambiguity seems a deliberate ploy to show that people can choose their future (e.g. 'State of Decay', Orthia 2013), but it is still ambiguous. While we might replace the science-beatstyranny template with a more generic '[insert-tool-here]-beats-tyranny' template, the effect is the same: if we follow Doctor Who's political programme, after defeating the tyrant we will not know where we are going or what it will look like when we get there.

In this article we have employed a structuralist approach to help understand how viewers can interpret the politics of Doctor Who in diverse and contradictory ways. Our identification of structural patterns common to numerous classic Doctor Who serials does not determine how each viewer will respond to the stories. Rather, it can help us understand why their responses are so different and how the inherent political ambiguity in television fiction is maintained.

A question remains about this structure's applicability to contemporary science fiction and fantasy television programmes. Classic Doctor Who was strongly serialized, with few plots continuing from one story to the next, so story resolutions were routinely required. But in the twenty-first century, speculative television increasingly follows a continuous story arc model (Charles 2007). That model may allow programmes to engage in deep debates about the political and ethical machinations of regime change. Future researchers might examine whether this renders their political commitments less ambiguous than in classic Doctor Who, and how that affects viewer interpretations. 


\section{Acknowledgements}

We thank three reviewers for their useful feedback on the manuscript.

\section{References}

Agamben, G. (2002), 'The state of emergency: Extract from a lecture given at the Centre RolandBarthes (Universite Paris VII, Denis-Diderot) in 2002', http://www.generationonline.org/p/fpagambenschmitt.htm. Accessed 23 April 2017.

Akers, L. G. (2010), 'Empathy, ethics and wonder', in C. Lewis and P. Smithka (eds), Doctor Who and Philosophy: Bigger on the Inside, Chicago: Open Court, pp. 145-56.

Barthes, R. (1988), 'The death of the author', in Image-Music-Text, translated by Heath, S., New York: Noonday Press, pp. 142-49.

Britton, P .D. (2011), TARDISbound: Navigating the Universes of Doctor Who, London, I. B. Tauris.

Chapman, J. (2006), Inside the TARDIS: The Worlds of Doctor Who: A Cultural History, London, I. B. Tauris.

Charles, A. (2007), 'The ideology of anachronism: television, history and the nature of time', in D. Butler (ed.), Time And Relative Dissertations In Space: Critical perspectives on Doctor Who, Manchester: Manchester University Press, pp. 108-22.

Chomsky, N. (1996), Class Warfare: Interviews with David Barsamian, London, Pluto Press.

Chow-White, P.A., Deveau, D. and Adams, P. (2015), 'Media encoding in science fiction television: Battlestar Galactica as a site of critical cultural production', Media, Culture \& Society, 37: 8, pp. 1210-25.

de Kauwe, V. (2013), 'Through coloured eyes: An alternative viewing of postcolonial transition', in L. Orthia (ed.), Doctor Who and Race, Bristol: Intellect, pp. 141-57.

Decker, K. S. (2010), 'The ethics of the Last of the Time Lords', in C. Lewis and P. Smithka (eds.), Doctor Who and Philosophy: Bigger on the Inside, Chicago: Open Court, pp. 133-43.

Fiske, J. (1984), 'Popularity and ideology: A structuralist reading of Dr. Who', in W. D. Rowland and B. Watkins (eds.), Interpreting Television: Current Research Perspectives, Beverly Hills: Sage Publications, pp. 165-98.

Gregg, P. B. (2004), 'England looks to the future: The cultural forum model and Doctor Who', Journal of Popular Culture, 37: 4, pp. 648-61.

Harding, S. (2008), Sciences From Below: Feminisms, Postcolonialities, and Modernities, Durham, Duke University Press.

Herman, D. (2010), 'Structuralist Narratology', in D. Herman, M. Jahn and M-L. Ryan (eds), Routledge Encyclopedia of Narrative Theory, London: Routledge, online.

Hutchens, G. (2016), “Unelected swill”: One Nation senator Malcolm Roberts calls for Australia to leave UN', The Guardian, 13 September, https://www.theguardian.com/australianews/2016/sep/13/unelected-swill-one-nation-senator-malcolm-roberts-calls-for-australia-toleave-un. Accessed 15 January 2017.

Lavender III, I. (2009), 'Critical race theory', in M. Bould, A. M. Butler, A. Roberts and S. Vint (eds), The Routledge Companion to Science Fiction, Abingdon: Routledge, pp. 185-93.

Lucas, G. (1977), Star Wars: Twentieth Century Fox.

McKee, A. (2004), 'Is Doctor Who political?', European Journal of Cultural Studies, 7, pp. 201-17.

Merchant, C. (1980), The Death of Nature: Women, Ecology, and the Scientific Revolution, San Francisco, HarperCollins.

Meyer, G. (2016), 'In science communication, why does the idea of a public deficit always return?', Public Understanding of Science, 25: 4, pp. 433-46.

Orthia, L. A. (2010), "Sociopathetic abscess" or "yawning chasm"? The absent postcolonial transition in Doctor Who', Journal of Commonwealth Literature, 45: 2, pp. 207-25.

Orthia, L. A. (2011), 'Antirationalist critique or fifth column of scientism? Challenges from Doctor Who to the mad scientist trope', Public Understanding of Science, 20, pp. 525-42. 
Orthia, L. A. (2013), 'Savages, science, stagism and the naturalized ascendancy of the Not-We in Doctor Who', in L. Orthia (ed.), Doctor Who and Race, Bristol: Intellect, pp. 269-87.

Orthia, L.A. \& Morgain, R. (2016), 'The gendered culture of scientific competence: A study of scientist characters in Doctor Who 1963-2013', Sex Roles, 75, pp. 79-94.

Orwell, G. (1946), Politics and the English Language, eBook version published by The University of Adelaide 17 December 2014, https://ebooks.adelaide.edu.au/o/orwell/george/o79p/.

Riggio, A. (2010), 'Overcoming evil, and spite, and resentment, and revenge', in C. Lewis and P. Smithka (eds), Doctor Who and Philosophy: Bigger on the Inside, Chicago: Open Court, pp. 249-59.

Sandifer, P. (2012), 'The Original Viking Settlers (Terminus)', http://www.eruditorumpress.com/blog/the-original-viking-settlers-terminus/. Accessed 25 April 2017.

Selden, R. (2014), Practising Theory and Reading Literature: An Introduction, Oxon, Routledge.

Speaker to Animals. (n.d.), 'John Fiske: Popularity \& Ideology: A Structuralist Reading of Dr Who', https://speakertoanimals.wordpress.com/television/doctor-who/making-doctor-whomean/popularity-and-ideolog/. Accessed 15 January 2017.

Tulloch, J. and Alvarado, M. (1983), Doctor Who: The Unfolding Text, London, Macmillan Press.

Tulloch, J. and Jenkins, H. (1995), Science Fiction Audiences: Watching Doctor Who and Star Trek, London, Routledge.

Vibert, F. (2007), The Rise of the Unelected: Democracy and the New Separation of Powers, Cambridge, Cambridge University Press.

Walker, D. (2007), 'Going after scientism through science fiction', Extrapolation, 48: 1, pp. 152-67.

\section{Television programmes}

Battlestar Galactica (2004-09, US: Sci-Fi Channel).

Doctor Who (1963-89; 1996; 2005-, UK: BBC).

'The Krotons' (28 December 1968-18 January 1969).

'The Green Death' (19 May-23 June 1973).

'The Monster of Peladon' (23 March-27 April 1974).

'The Ark in Space' (25 January-15 February 1975).

'The Creature from the Pit' (27 October-17 November 1979).

'State of Decay' (22 November-13 December 1980).

'Snakedance' (18-26 January 1983).

'Terminus' (15-23 February 1983). 


\section{Contributor Details}

Vanessa de Kauwe is a $\mathrm{PhD}$ candidate at the Australian National University who has published on racial and post-colonial representations in Doctor Who. Her background includes ethics and disability studies, and her current research involves developing science activities for the social integration of young people with disabilities.

Lindy Orthia is a senior lecturer in science communication who has published extensively on representations of science in Doctor Who. Her research interests include science and popular fiction and the history of science communication.

\section{Contact Details}

Corresponding author: Lindy Orthia

CPAS, Peter Baume Building 42A, The Australian National University, Acton ACT 2601, Australia Contact: lindy.orthia@anu.edu.au

NB. Vanessa de Kauwe and Lindy Orthia share first authorship for this work. 